\title{
Camelid VHH Antibodies that Neutralize Botulinum Neurotoxin Serotype E Intoxication or Protease Function
}

\author{
Jacqueline M. Tremblay ${ }^{1}$, Edwin Vazquez-Cintron ${ }^{2}{ }^{\oplus}$, Kwok-Ho Lam ${ }^{3}$, Jean Mukherjee ${ }^{1}$, \\ Daniela Bedenice ${ }^{4}$, Celinia A. Ondeck ${ }^{2}$, Matthieu T. Conroy ${ }^{2}$, Skylar M. L. Bodt ${ }^{2}$ (D, \\ Brittany M. Winner ${ }^{2}$, Robert P. Webb ${ }^{5}(\mathbb{D})$, Konstantin Ichtchenko ${ }^{6}\left(\mathbb{D}\right.$, Rongsheng Jin ${ }^{3}(\mathbb{D}$, \\ Patrick M. McNutt ${ }^{2}$ and Charles B. Shoemaker ${ }^{1, * \mathbb{D}}$ \\ 1 Department of Infectious Disease and Global Health, Cummings School of Veterinary Medicine, \\ Tufts University, North Grafton, MA 01536, USA; jacqueline.tremblay@tufts.edu (J.M.T.); \\ jean.mukherjee@gmail.com (J.M.) \\ 2 The United States Army Medical Research Institute of Chemical Defense, Fort Detrick, MD 21010, USA; \\ ejv.cintron@gmail.com (E.V.-C.); condeck@genevausa.org (C.A.O.); matthieu.t.conroy.ctr@mail.mil (M.T.C.); \\ smlbodt@gmail.com (S.M.L.B.); winnerbr@msu.edu (B.M.W.); patrick.m.mcnutt2.mil@mail.mil (P.M.M.) \\ 3 Department of Physiology \& Biophysics, University of California, Irvine, CA 92697-4560, USA; \\ kwokhl@uci.edu (K.-H.L.); r.jin@uci.edu (R.J.) \\ 4 Department of Clinical Sciences, Cummings School of Veterinary Medicine, Tufts University, North Grafton, \\ MA 01536, USA; daniela.bedenice@tufts.edu \\ 5 Bacteriology Division, U.S. Army Medical Research Institute of Infectious Diseases, Ft. Detrick, \\ MD 21702-5011, USA; rpwebb2406@gmail.com \\ 6 Department of Biochemistry and Molecular Pharmacology, New York University School of Medicine, \\ New York, NY 10016, USA; Konstantin.Ichtchenko@nyulangone.org \\ * Correspondence: charles.shoemaker@tufts.edu
}

Received: 18 August 2020; Accepted: 11 September 2020; Published: 24 September 2020

check for updates

\begin{abstract}
Botulinum neurotoxin (BoNT) serotype $\mathrm{E}$ is one of three serotypes that cause the preponderance of human botulism cases and is a Tier 1 Select Agent. BoNT/E is unusual among BoNT serotypes for its rapid onset and short duration of intoxication. Here we report two large panels of unique, unrelated camelid single-domain antibodies (VHHs) that were selected for their ability to bind to BoNT/E holotoxin and/or to the BoNT/E light chain protease domain (LC/E). The 19 VHHs which bind to BoNT/E were characterized for their subunit specificity and 8 VHHs displayed the ability to neutralize BoNT/E intoxication of neurons. Heterodimer antitoxins consisting of two BoNT/E-neutralizing VHHs, including one heterodimer designed using structural information for simultaneous binding, were shown to protect mice against co-administered toxin challenges of up to 500 MIPLD 50 . The 22 unique VHHs which bind to LC/E were characterized for their binding properties and 9 displayed the ability to inhibit LC/E protease activity. Surprisingly, VHHs selected on plastic-coated LC/E were virtually unable to recognize soluble or captured LC/E while VHHs selected on captured LC/E were poorly able to recognize LC/E coated to a plastic surface. This panel of anti-LC/E VHHs offer insight into BoNT/E function, and some may have value as components of therapeutic antidotes that reverse paralysis following BoNT/E exposures.
\end{abstract}

Keywords: botulinum neurotoxin; botulism; toxin; antitoxin; single-domain antibody; $\mathrm{VHH}$; neutralization; protease

Key Contribution: Numerous high affinity VHH antibodies binding to BoNT/E and LC/E are reported together with their characterizations. Heteromultimers of BoNT/E-neutralizing VHHs potently protect mice from BoNT/E intoxication. 


\section{Introduction}

Botulinum neurotoxins (BoNTs) are considered among the most dangerous bioweapon threats (Tier 1 agent, USA Federal Select Agent Program) as a consequence of their extreme toxicity, widespread availability and relative ease of production. BoNTs are also the cause of natural botulism from food poisoning or wound infections. While at least eight different BoNT serotypes are known to exist in nature, serotypes A, B and E are responsible for the vast majority of human cases of botulism [1]. Treatments for exposure to BoNTs are currently limited to antiserum-derived products consisting of purified anti-BoNT polyclonal antibodies (BabyBIG) [2] or $\mathrm{F}\left(\mathrm{ab}^{\prime}\right)_{2}$ immunoglobulin fragments derived from equine plasma (HBAT) [3]. Pools of humanized anti-BoNT monoclonal antibodies (mAbs) are being developed to replace the antiserum-based products $[4,5]$. These new and highly effective therapeutics consist of pools of three different $\mathrm{mAbs}$ for each BoNT serotype, a factor which complicates their manufacture and increases their cost of production. There is no current antidote for patients in which BoNT has already entered motor neurons and begun to cause flaccid paralysis. Some success has been reported in reversing botulism paralysis with the voltage-gated potassium channel inhibitor 3,4-diaminopyridine (3,4-DAP) [6], and atoxic BoNT vehicles are being developed to deliver biomolecular inhibitors of BoNT proteases to intoxicated neurons [7].

Several research teams have developed camelid single-domain antibodies (called VHHs or nanobodies) as components of antitoxin and antidote products (reviewed by [8,9]). These simple binding agents, which contain the $\mathrm{V}_{\mathrm{H}}$ region of heavy chain-only antibodies, are small ( $\left.\sim 14 \mathrm{kDa}\right)$ proteins that are stable to a wider range of $\mathrm{pH}$ and temperatures than $\mathrm{mAbs}$ and can be produced inexpensively in microbial hosts [10]. Importantly, VHHs can be expressed as multimers, which impart improved antitoxin potencies [11-13] and permit the targeting of multiple toxins or natural toxin variants using a single protein [14-18]. VHH serum persistence can be extended by the addition of an albumin-binding peptide [12] and their in vivo efficacy can be significantly enhanced by co-administering epitopically tagged VHH agents with an anti-tag mAb that promotes toxin clearance [12,19]. VHHs are amenable to genetic delivery and can be expressed for extended times in patients by gene therapy with viral vectors [12] or encapsulated synthetic mRNA [20].

We and others have reported the identification of VHH-based agents that either neutralize BoNT/A or BoNT/B intoxication of cells or inhibit light chain protease domains within the neuronal cytosol [21-25]. Bakherad et al. [26] reported a VHH that neutralized BoNT/E and partially protected against intoxication in mice. VHH-based neutralizing agents (VNAs) consisting of two linked neutralizing VHH components have proven highly effective in protecting mice from BoNT/A and BoNT/B intoxication when administered as proteins [21,25], on red blood cells [27], or by gene therapy $[12,20]$, offering novel therapeutic options for botulism.

Here, we report the characterization of two panels of 37 unrelated, unique VHHs that bind to BoNT/E holotoxin and/or the isolated BoNT/E light chain protease domain (LC/E). VHHs were characterized for the ability to neutralize BoNT/E intoxication of neurons and/or to inhibit LC/E protease cleavage of Synaptosomal-Associated Protein, 25kDa (SNAP-25). To test their in vivo potential as antitoxins, several VHH heterodimeric VNAs were prepared and compared for their BoNT/E antitoxin potencies in mice, including one 'designer' VNA consisting of two closely apposed VHHs linked for simultaneous binding to BoNT/E based on crystal structure data [28].

\section{Results}

\subsection{Discovery and Characterization of BoNT/E and LC/E Binding VHHs}

\subsubsection{Selection of VHHs Binding ciBoNTE or LC/E Adsorbed to Plastic}

Two pairs of alpacas (Vicugna pacos) were immunized with catalytically inactive BoNT/E (ciBoNTE) [29] and/or LC/E (both subtype E1) as described in the Materials and Methods. VHH display phage libraries were prepared from lymphocyte RNA obtained from each pair of alpacas. Phage 
displaying VHHs from both libraries were initially selected for binding to ciBoNTE or LC/E proteins directly coated (adsorbed) on high protein-binding Nunc Maxisorp Immuno Tubes. Sequence analysis of VHHs recovered from selection on coated ciBoNTE or LC/E (Figure 1) identified nine VHH families, each comprised of VHHs having distinct homologies among the three complementarity-determining regions (CDRs). When $\mathrm{VHH}$ selection was performed on coated $\mathrm{LC} / \mathrm{E}$, eleven different $\mathrm{VHHs}$ were identified, however only one, JLF-H5, represented a unique family. The remaining VHHs were all members of the JLG-G12 family that was selected on plastic-adsorbed ciBoNTE (Figure 1). One representative of each of the nine VHH families (Tables 1 and 2) was chosen for expression, purification and characterization.

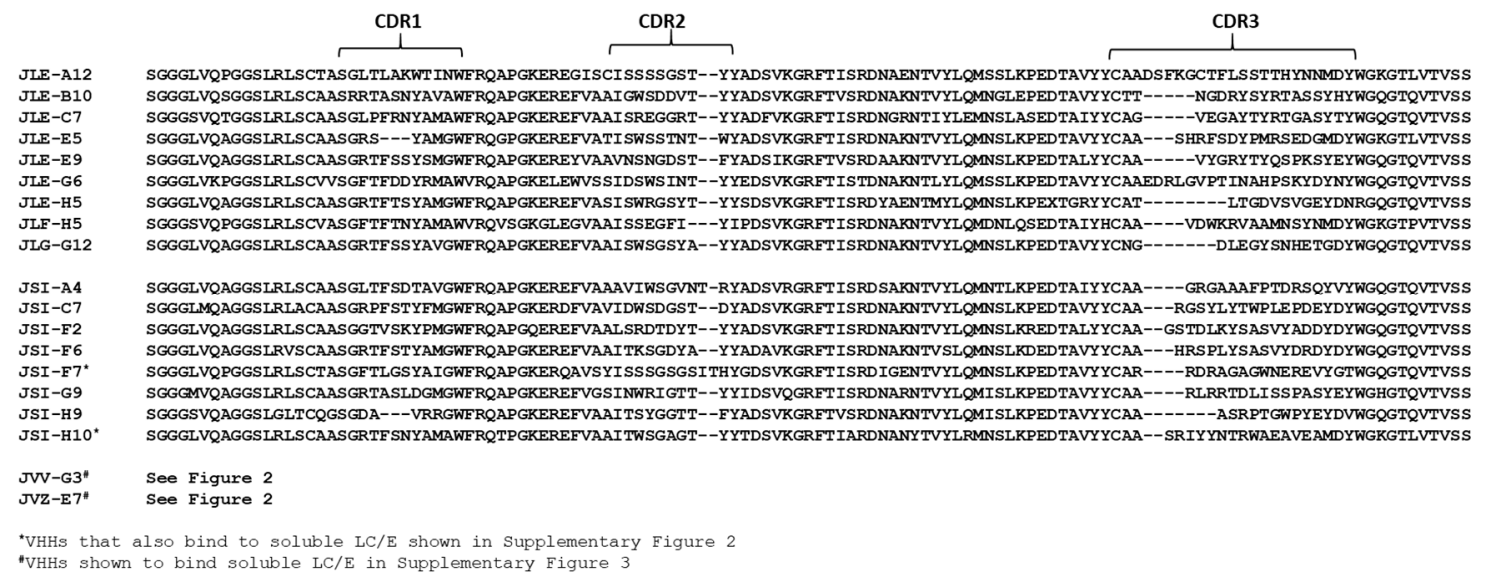

Figure 1. Sequence alignment of all catalytically inactive botulinum neurotoxin serotype E (ciBoNTE)binding camelid single-domain antibodies (VHHs) identified in this report. Amino acid sequences of all VHHs identified in this report that show clear binding to ciBoNTE on ELISAs employing plastic coated and/or antibody-captured ciBoNTE. Sequences are aligned to conserved framework regions and complementarity-determining regions (CDRs) are indicated.

Competition studies performed among the nine unique ciBoNTE-binding VHHs identified a total of four non-overlapping epitopes (competition groups 1 to 4 , Table 1). One epitope on ciBoNTE was recognized by the LC/E-binding VHHs, JLG-G12 and JLF-H5, while the other three epitopes were recognized by the seven remaining VHHs. When assessed by dilution ELISAs performed with ciBoNTE coated on high protein-binding plastic, the different ciBoNTE-binding VHHs displayed unusual variations in peak target binding at high VHH concentrations (Figure S1). In an attempt to explain this observation, we repeated the dilution ELISAs after adsorbing ciBoNTE onto a more hydrophilic tissue culture plastic (Costar) [30]. Surprisingly, VHHs displayed dramatically different binding properties depending on the type of plastic used. For example, the two unique VHHs recognizing the LC/E domain (JLF-H5 and JLG-G12) both displayed much weaker $\mathrm{EC}_{50}$ values and reduced levels of target binding on tissue culture vs. protein-binding plastic, suggesting that these VHHs recognize an epitope that is poorly represented in the soluble form of LC/E and becomes much more accessible when the target is coated onto a more hydrophobic plastic surface (Figure S1). This hypothesis was confirmed when we were able to use an antibody to 'capture' soluble LC/E and ELISAs found that JLF-H5 and JLG-G12 also displayed minimal LC/E recognition (Figure S1). In contrast, the remaining seven VHHs generally recognized ciBoNTE on tissue culture plastic much better than on protein-binding plastic, particularly in the percent of target binding (Figure S1). These VHHs were also tested by ELISA for recognition of the amino or carboxyl terminal domains of the BoNT/E heavy chain $\left(\mathrm{H}_{N} \mathrm{E}\right.$ and $\mathrm{H}_{\mathrm{C}} \mathrm{E}$; Tables 1 and 2) and only two VHHs bound to either protein. The remaining five VHHs therefore recognize multi-domain epitopes of BoNT/E. In total, the ELISA results suggested that ciBoNTE-binding VHHs recognize conformational epitopes that become profoundly altered when ciBoNTE is coated onto different plastic surfaces. 
Table 1. Characterization of ciBoNTE-binding VHHs selected on plastic-adsorbed ciBoNTE or BoNT/E light chain protease domain (LC/E).

\begin{tabular}{|c|c|c|c|c|c|c|c|}
\hline $\begin{array}{l}\text { VHH } \\
\text { Name }\end{array}$ & $\begin{array}{c}\text { ciBoNTE-Binding } \\
\mathrm{EC}_{50}, \mathrm{nM} \\
\text { Nunc }^{\mathrm{A}}\end{array}$ & $\begin{array}{c}\text { ciBoNTE-Binding } \\
\mathrm{EC}_{50}, \mathrm{nM} \\
\text { Costar }^{\mathrm{A}}\end{array}$ & $\begin{array}{c}\mathrm{H}_{\mathrm{N}} \mathrm{E}-\text { Binding } \\
\mathrm{EC}_{50,}, \mathrm{nM} \\
\text { Costar }^{\mathrm{B}}\end{array}$ & $\begin{array}{c}\mathrm{H}_{\mathrm{C}} \mathrm{E}-\text { Binding } \\
\mathrm{EC}_{50,}, \mathrm{nM} \\
\text { Costar }^{\mathrm{B}}\end{array}$ & $\begin{array}{c}\text { LC/E-Binding }{ }^{\mathrm{A}} \\
\mathrm{EC}_{50}, \mathrm{nM} \\
\text { Nunc }^{\mathrm{A}}\end{array}$ & $\begin{array}{c}\text { BoNT/E } \\
\text { Neutralization } C\end{array}$ & $\begin{array}{l}\text { Competition } \\
\text { Group }{ }^{D}\end{array}$ \\
\hline JLE-A12 & 1 & 1 & NB & NB & NB & - & 1 \\
\hline JLE-C7 & 3 & 1 & NB & NB & NB & - & 1 \\
\hline JLE-E5 & 1 & 1 & NB & NB & NB & + & 2 \\
\hline JLE-G6 & 1 & 20 & NB & 3 & NB & + & 3 \\
\hline JLE-H5 & 10 & $>50$ & 20 & NB & NB & - & 1 \\
\hline JLF-H5 & 20 & $>100$ & NB & NB & 10 & - & 4 \\
\hline JLG-G12 & 3 & $>100$ & NB & NB & 2 & - & 4 \\
\hline
\end{tabular}

\subsubsection{Selection of VHHs Recognizing Antibody-Captured ciBoNTE}

Given data that ciBoNTE conformation was substantially changed when coated onto Maxisorp plastic, we repeated the selection process employing ciBoNTE that was captured from solution by an antibody. Specifically, the second round of $\mathrm{VHH}$ discovery was performed by panning the $\mathrm{VHH}$ display phage library on ciBoNTE had been captured using VHH, JLE-E5. Using the capture method of selection, we identified eight new unique VHH families (JSI series, Table 2, Figure S2) in addition to re-discovering several of the VHHs identified in the prior screens. Seven of the new series of VHHs strongly recognized $\mathrm{VHH}$-captured ciBoNTE on ELISAs with high affinity $\left(\mathrm{EC}_{50} \leq 1 \mathrm{nM}\right)$. Two of these VHHs (JSI-F7 and JSI-H10) also recognize the VHH-captured form of LC/E (see below).

Competition studies on the JSI series of VHHs indicated that all recognized epitopes that did not overlap with epitopes bound by the VHHs in Table 1 and comprised six new competition groups (Table 2). Two additional ciBoNTE-binding VHHs were identified later among VHHs selected for binding to LC/E (see below). These VHHs (JVV-G3, JVZ-E7) recognize a new epitope on ciBoNTE and their characterization information is included in Table 2. The sequences of all VHHs representing the unique, ciBoNTE-binding VHH families identified through our various panning strategies are included in Figure 1.

Table 2. Characterization of ciBoNTE-binding VHHs selected on VHH-captured ciBoNTE or LC/E.

\begin{tabular}{|c|c|c|c|c|c|c|}
\hline $\begin{array}{l}\text { VHH } \\
\text { Name }\end{array}$ & $\begin{array}{l}\text { ciBoNTE-Binding } \\
\text { EC }_{50}, \text { nM Captured }^{\mathrm{A}}\end{array}$ & $\begin{array}{l}\text { LC/E-Binding } \text { EC }_{50} \\
\text { nM Captured }{ }^{A}\end{array}$ & $\begin{array}{l}\mathrm{H}_{\mathrm{N}} \mathrm{E}-\mathrm{Binding} \mathrm{EC}_{50} \\
\text { nM Costar }{ }^{\mathrm{B}}\end{array}$ & $\begin{array}{c}\mathrm{H}_{\mathrm{C}} \mathrm{E}-\mathrm{Binding} \mathrm{EC}_{50}, \\
\text { nM Costar }\end{array}$ & $\begin{array}{c}\text { BoNT/E } \\
\text { Neutralization }\end{array}$ & $\begin{array}{l}\text { Competition } \\
\text { Group }^{D}\end{array}$ \\
\hline JSI-A4 & 10 & NB & NB & NB & + & 5 \\
\hline JSI-F2 & 0.5 & NB & NB & 2 & + & 7 \\
\hline JSI-F6 & 1 & NB & NB & 3 & - & 8 \\
\hline JSI-H9 & 0.6 & NB & $>100$ & NB & - & 6 \\
\hline JSI-H10 & 0.2 & 0.4 & NB & NB & - & 6 \\
\hline JVV-G3 E & 2 & 0.6 & ND & ND & - & 11 \\
\hline JVZ-E7 E & 3 & 0.4 & ND & ND & - & 11 \\
\hline
\end{tabular}

${ }^{\mathrm{A}} \mathrm{EC}_{50}$ estimates based on dilution ELISAs with ciBoNTE captured by JLE-E5 or JSI-F7 (Figure S2). ${ }^{\mathrm{B}} \mathrm{EC}_{50}$ estimates based on dilution ELISAs (not shown). ${ }^{C}$ BoNT/E neutralization based on assays shown in Figure 3 . D Distinct epitopes based on competition analysis (see Methods). ${ }^{\mathrm{E}}$ Additional characterization shown in Table 3. 


\subsubsection{Selection of VHHs Recognizing VHH-Captured LC/E}

Initial screening efforts using LC/E coated to plastic (above) discovered two VHH families that formed a single competition group, represented by JLG-G12 and JLF-H5. Notably, both of these VHHs exhibited poor binding to captured, soluble LC/E. Hypothesizing that adsorption of LC/E to the protein-binding plastic disrupts and unfolds the native, soluble LC/E structure, we re-panned VHH display phage libraries using LC/E captured to a surface with VHH JSI-F7 (Table 2). By re-panning against captured LC/E, we discovered twenty new, unique VHH families (Figure 2). Remarkably, these VHHs showed virtually no recognition of LC/E coated on protein-binding or tissue culture plastic in dilution ELISAs (Figure S3; Table 3). However, these VHHs displayed strong binding to the soluble, VHH-captured LC/E, including $19 \mathrm{VHHs}$ showing $\mathrm{EC}_{50} \leq 1 \mathrm{nM}$. The extreme variations in VHH binding between plastic-coated and captured LC/E further supports the hypothesis of major conformation differences between captured and adsorbed targets.

Given the high affinity of VHHs selected by captured LC/E, we hypothesized a subset of these VHHs would inhibit LC/E protease function. Indeed, nine VHHs clearly inhibited LC/E protease cleavage of a recombinant SNAP-25 following a $1.5 \mathrm{~h}$ incubation (Figure S4A; Table 3). Several of these VHHs (e.g., JVV-A3, JVV-B3 and JVV-G7) displayed unusual persistence by maintaining strong LC/E protease inhibition after an 18-h incubation time (Figure S4B). The full set of LC/E-binding VHHs were also tested for protease inhibition in a FRET-based SNAP-25 cleavage assay, Figure S4C. Using this assay, seven of the nine previously identified LC/E protease-inhibitory VHHs reproducibly inhibited SNAP25 cleavage by LC/E, while the remaining two VHHs displayed variable inhibitory activity (Table 3).

Table 3. Characterization of soluble LC/E-binding VHHs.

\begin{tabular}{|c|c|c|c|c|}
\hline $\begin{array}{l}\text { VHH } \\
\text { Name }\end{array}$ & $\begin{array}{c}\text { LC/E-Binding } \mathrm{EC}_{50}(\mathrm{nM}) \\
\text { Nunc } \mathrm{A}\end{array}$ & $\underset{\text { Costar }^{\mathrm{A}}}{\text { LC/E-Binding } \mathrm{EC}_{50}(\mathrm{nM})}$ & $\begin{array}{l}\text { LC/E-Binding } \mathrm{EC}_{50}(\mathrm{nM}) \\
\text { JSI-F7-Captured }\end{array}$ & $\begin{array}{l}\text { LC/E Protease } \\
\text { Inhibition }\end{array}$ \\
\hline JSI-F7 ${ }^{\mathrm{B}}$ & $>25$ & $>25$ & $>25 *$ & - \\
\hline JSI-H10 B & $>25$ & $>25$ & 0.03 & - \\
\hline JVV-A3 & $>25$ & $>25$ & 0.4 & ++ \\
\hline JVV-A8 & $>25$ & $>25$ & 0.8 & ++ \\
\hline JVV-B3 & $>25$ & 10 & 0.4 & ++ \\
\hline JVV-C12 & $>25$ & 10 & 0.2 & - \\
\hline JVV-D4 & $>25$ & $>25$ & 0.4 & - \\
\hline JVV-D5 & $>25$ & $>25$ & 0.2 & - \\
\hline JVV-D9 & $>25$ & 5 & 0.2 & - \\
\hline JVV-E8 & $>25$ & $>25$ & 0.2 & - \\
\hline JVV-E10 & $>25$ & $>25$ & 0.4 & ++ \\
\hline JVV-E12 & $>25$ & $>25$ & 0.8 & - \\
\hline JVV-F4 & $>25$ & $>25$ & 0.2 & - \\
\hline JVV-F6 & $>25$ & 2 & 0.4 & - \\
\hline JVV-G3 ${ }^{B}$ & $>25$ & $>25$ & 0.6 & + \\
\hline JVV-G7 & $>25$ & $>25$ & 0.4 & ++ \\
\hline JVV-G10 & $>25$ & $>25$ & 0.4 & - \\
\hline JVV-H9 & $>25$ & $>25$ & 1 & - \\
\hline JVV-H12 & $>25$ & 10 & 0.4 & ++ \\
\hline JVZ-E7 B & $>25$ & $>25$ & 0.4 & + \\
\hline JVZ-G1 & $>25$ & $>25$ & 2 & - \\
\hline JVZ-H5 & $>25$ & $>25$ & 0.4 & ++ \\
\hline
\end{tabular}




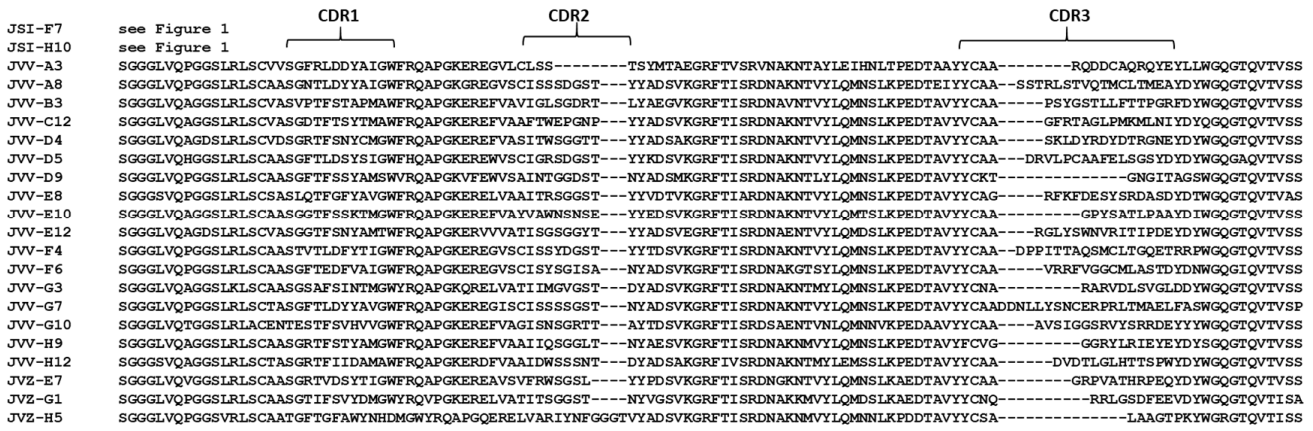

Figure 2. Sequence alignment of all LC/E-binding VHHs identified in this report. Amino acid sequences of all VHHs identified in this report that show clear binding to LC/E on ELISAs employing captured LC/E. Sequences are aligned to conserved framework regions and CDRs are indicated.

\subsection{VHH and VNA Neutralization of BoNT/E Intoxication}

\subsubsection{VHH Monomer Neutralization of BoNT/E in Neuronal Cultures}

All unique VHHs that displayed clear binding to ciBoNTE by ELISA (Tables 1 and 2) were tested for the ability to prevent BoNT/E intoxication of rat E18 primary neuron cultures between 17-21 days in vitro (DIV; Figure 3A; Figure S5) [31]. VHHs were added at a high stoichiometric ratio (200 nM VHH to $16.8 \mathrm{pM}$ BoNT/E) to increase the sensitivity of detecting neutralization. Following overnight incubation, eight unique VHHs were identified that reduced SNAP-25 cleavage by greater than $75 \%$ (Figure 3A). All VHHs recognizing LC/E in Table 3 were also tested and unsurprisingly showed no significant BoNT/E-neutralizing activity (Figure S6). Three BoNT/E-neutralizing VHHs (JLE-E5, JLE-E9 and JLE-G6) were identified among the VHHs selected on coated ciBoNTE (Table 1). In co-crystallization studies, JLE-E5 and JLE-E9 have now been studied for their mechanisms of neutralization and both were shown to neutralize intoxication by inhibiting BoNT/E endosomal membrane association [28]. JLE-G6 binds to the $\mathrm{H}_{\mathrm{C}} \mathrm{E}$ receptor binding domain of BoNT/E, and thus likely neutralizes the toxin by inhibiting its ability to bind its neuronal receptors, SV2 and/or gangliosides [25]. Five additional BoNT/E-neutralizing VHHs were identified among JSI series VHHs selected on captured ciBoNTE (JSI-A4, JSI-C7, JSI-F2 and JSI-G9). No experimental data regarding their mechanisms of neutralization are yet available for these VHHs, although, like JLE-G6, JSI-F2 binds to the $\mathrm{H}_{\mathrm{C}} \mathrm{E}$ receptor binding domain.

A

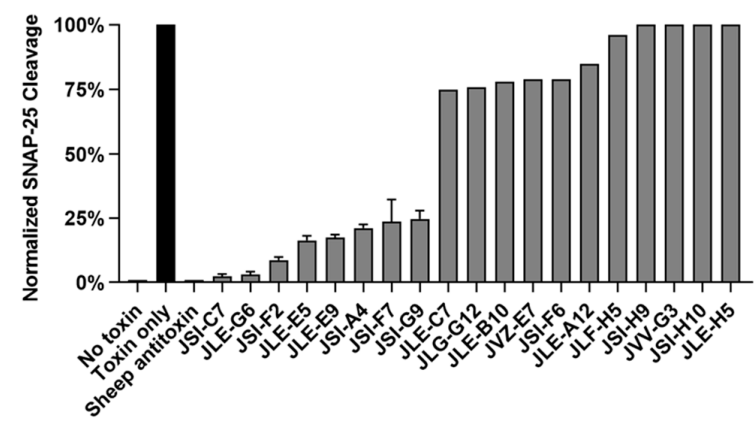

B

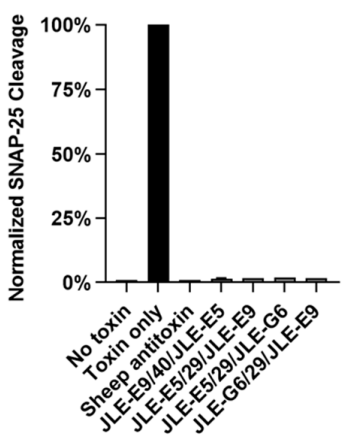

Figure 3. Cell-based assays of all VHH monomers for BoNT/E neutralization. E18 primary rat cortical neurons (17-21 d in culture) were co-incubated with $200 \mathrm{nM} \mathrm{VHH}$ or VHH-based neutralizing agents (VNAs) and $16.7 \mathrm{pM}$ BoNT/E (corresponding to $20 \mathrm{MIPLD}_{50} / \mathrm{mL}$ ) for $24 \mathrm{~h}$ prior to harvest and immunoblot analysis. SNAP-25 cleavage levels were normalized to toxin-only controls within each experiment and averaged among experiments for VHHs that showed efficacy. (A) Summary of cell-based SNAP-25 cleavage assays for all BoNT/A holotoxin-binding VHHs and control treatments. (B) Summary of SNAP-25 cleavage assays for all heterodimer VNAs and control treatments. 


\subsubsection{VHH Monomer Neutralization of BoNT/E in Mice}

We next tested the eight BoNT/E-neutralizing monomer VHHs ( $2 \mu \mathrm{g}$ given intravenously) for their ability to protect mice from a co-administered challenge dose of 3 MIPLD ${ }_{50}$ BoNT/E (Figure S7A). Three VHHs were protective under these conditions: JSI-C7, JSI-F7 and JSI-G9, each of which were identified using captured ciBoNT/E. None were protective against a 10 MIPLD 50 BoNT/E challenge (Figure S7B).

\subsubsection{VHH Heterodimer Neutralization of BoNT/E in Mice}

Previous studies have demonstrated that expression of VHH heterodimeric VNAs composed of two BoNT-neutralizing VHHs can radically improve in vivo antitoxin potencies [21,25]. To similarly increase the potency of BoNT/E VHHs, we initially engineered and produced VHH heterodimer VNAs using the three BoNT/E-neutralizing VHHs identified in the first screen: JLE-E5, JLE-E9 and JLE-G6. The VNAs were expressed in three different heterodimer combinations, each with the VHH components separated by a 29 amino acid spacer: JLE-E5/29/JLE-E9; JLE-E5/29/JLE-G6 and JLE-G6/29/JLE-E9.

We next produced a fourth 'designer' VNA by incorporating new structural information [28] predicted to result in enhanced neutralization properties [25]. Prior studies showed that creating bivalent VNAs that could bind simultaneously to the target is an efficient strategy to increase affinity and potency. The binding of the first $\mathrm{VHH}$ is an intermolecular event with the affinity comparable to that of the monovalent $\mathrm{VHH}$, while the second $\mathrm{VHH}$ will bind via an intramolecular interaction. The effective concentration $\left(\mathrm{C}_{\text {eff }}\right)$ is increased for the second $\mathrm{VHH}$ once the first $\mathrm{VHH}$ is bound to substantially increase the affinity of the bivalent VNA compared with the individual VHH components. The $\mathrm{C}_{\text {eff }}$ depends on several factors including the end-to-end distance of the two VHHs, which can be estimated using structural information [32], and the properties and length of the peptide linker. Based on the precise binding sites for JLE-E5 and JLE-E9, which bind to closely apposed epitopes on BoNT/E [28], we engineered a VNA called JLE-E9/40/JLE-E5 which was predicted to have the optimal VHH orientation and spacer length to facilitate the ability of both VHH components to bind simultaneously to their BoNT/E epitopes (Figure 4A,B). To test for simultaneous binding, we performed gel filtration studies (Figure 4C) as previously reported [25]. Co-incubation of JLE-E9/40/JLE-E5 or JLE-E5/29/JLE-E9 with a two-fold molar excess of BoNT/E produced a single peak upon gel filtration, representing the heterodimeric BoNT/E-VNA complex expected when both VHHs are bound to the same molecule (Figure 4C). The high affinities of these VNAs to BoNT/E exceed the detection limits of in vitro assays and are not useful to experimentally differentiate the binding properties of these two VNAs. However, computer modeling can predict affinities and this analysis estimates that the designer VNA JLE-E9/40/JLE-E5 will have a substantially higher binding affinity compared with JLE-E5/29/JLE-E9 (Figure 4B). Neutralization studies in primary neurons revealed that all four VNAs potently blocked BoNT/E intoxication but could not differentiate the potencies of the different VNAs (Figure 3B).

The ability of VNAs to neutralize BoNT/E was tested in mice by intravenous administration of 40 pmol VNA with 10-1000 LD 50 of BoNT/E (approximately 0.01-1.0 pmol per mouse). JLE-E5/29/JLE-G6 or JLE-G6/29/JLE-E9 fully protected against $100 \mathrm{LD}_{50} \mathrm{BoNT/E}$ challenge but were ineffective in preventing mortality at $200 \mathrm{LD}_{50}$ challenge (Figure 5A,B). Mice treated with JLE-E5/29/JLE-E9 had 63\% survival when challenged with $50 \mathrm{LD}_{50}$ of BoNT/E but $0 \%$ survival at $100 \mathrm{LD}_{50}$ (Figure $5 \mathrm{C}$ ). These results were highly consistent with early pilot studies with three of the VNAs performed in a second laboratory

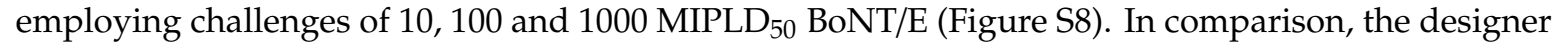
VNA engineered with optimized orientation and spacer, JLE-E9/40/JLE-E5, fully protected mice co-administered $200 \mathrm{LD}_{50}$ BoNT/E, partially protected mice at $500 \mathrm{LD}_{50}$, and did not protect mice from $1000 \mathrm{LD}_{50}$ (Figure 5D). Optimization of linker length increased neutralizing potency by approximately 10-fold. In addition, the designer VNA was significantly more potent than JLE-E5/29/JLE-G6 and JLE-G6/29/JLE-E9 (Figure 5E). Future studies will prioritize designer VNAs composed of more potent BoNT-neutralizing VHHs from the JSI series once their BoNT/E binding sites are identified and their mechanisms of toxin neutralization are elucidated. 
A

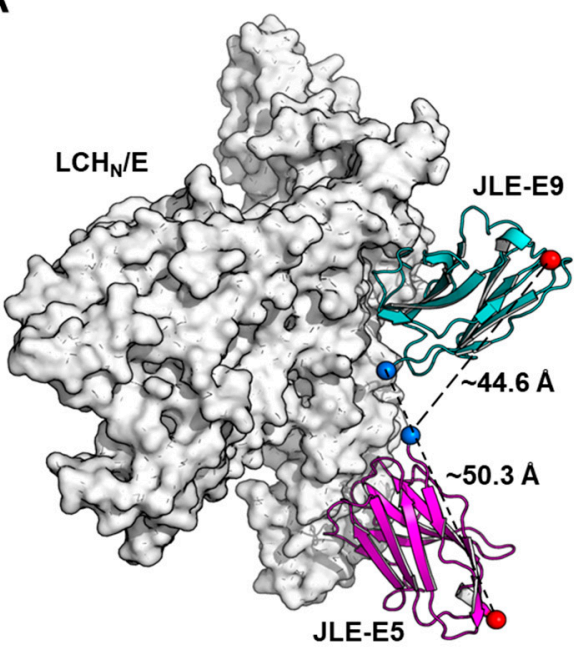

B

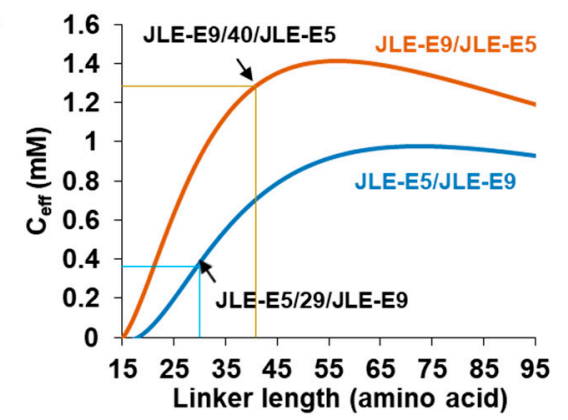

Normalized intensity

C
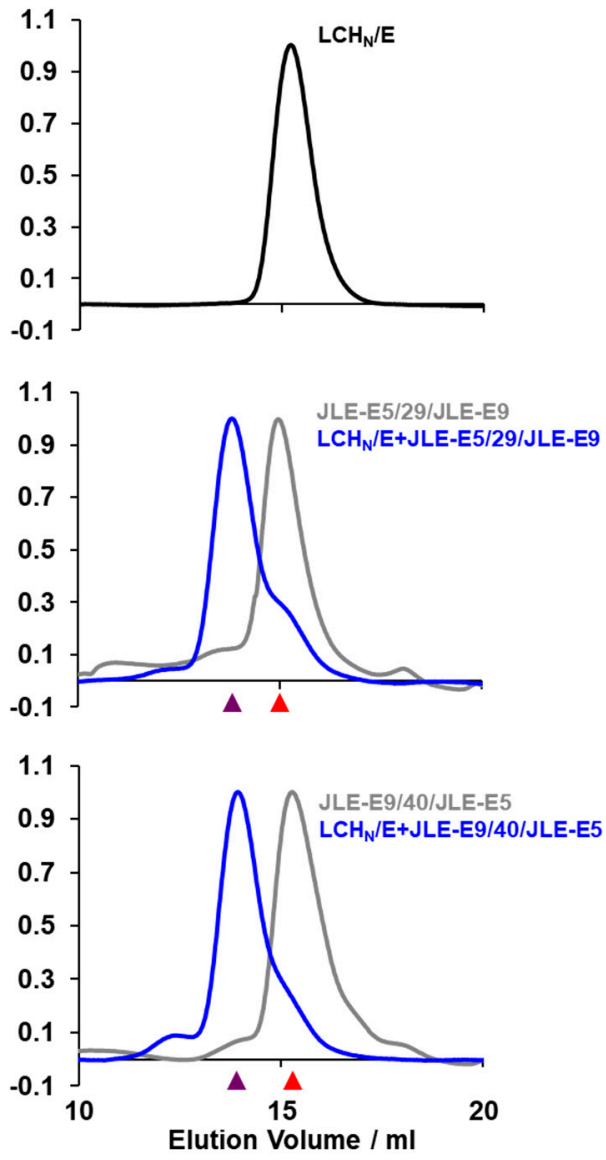

Figure 4. Structure-based design of a VNA optimized for simultaneous binding. (A) Inter-molecular distances between JLE-E5 and JLE-E9. The C $\alpha$ atoms of the $\mathrm{N}$ - and C-terminal residues are shown in blue and red spheres, respectively. (B) Calculated effective concentration $\left(\mathrm{C}_{\text {eff }}\right)$ of tethering JLE-E5 and JLE-E9 in opposite orientations by various linker lengths. The $\mathrm{C}_{\text {eff }}$ is calculated based on the inter-molecular distances between JLE-E5 and JLE-E9 (a) and according to equation reported in Zhou, 2003 [32], assuming the persistence length of $4.5 \AA$ and the nearest $\mathrm{C} \alpha-\mathrm{C} \alpha$ distance of $3.8 \AA$. (C) Gel filtration analysis. Elution profiles were shown for the $\mathrm{LCH}_{\mathrm{N}} / \mathrm{E}$ alone (top panel), or in complex with JLE-E5/29/JLE-E9 (middle panel), or JLE-E9/40/JLE-E5 (bottom panel). The toxin fragment was incubated with VNAs at 2:1 (blue curve) molar ratio. The elution profiles of the free VNAs are colored gray. The peak elution volumes of the monomeric $\mathrm{LCH}_{\mathrm{N}} / \mathrm{E}-\mathrm{VNA}$ complex and the VNA alone are indicated by purple and red arrows, respectively.

A

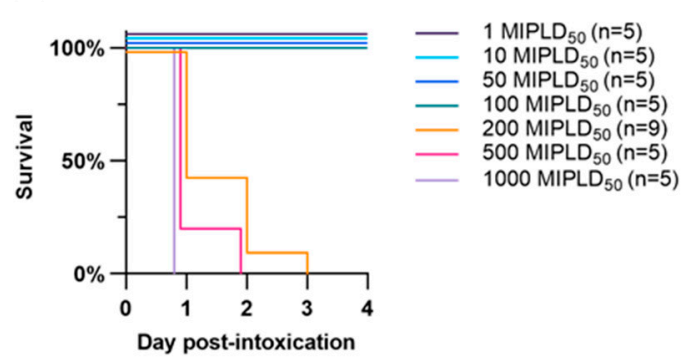

B JLE-G6/29/JLE-E9

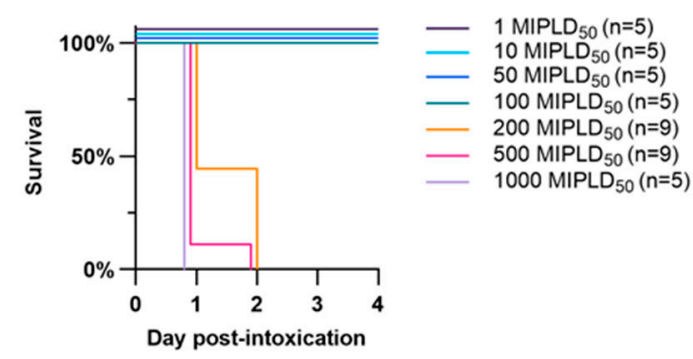

Figure 5. Cont. 
C

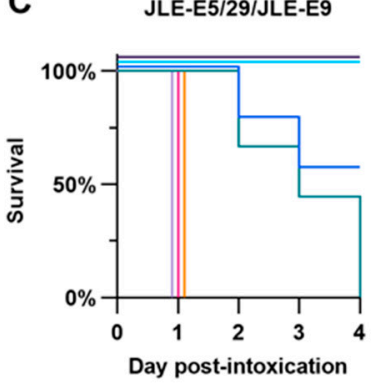

D

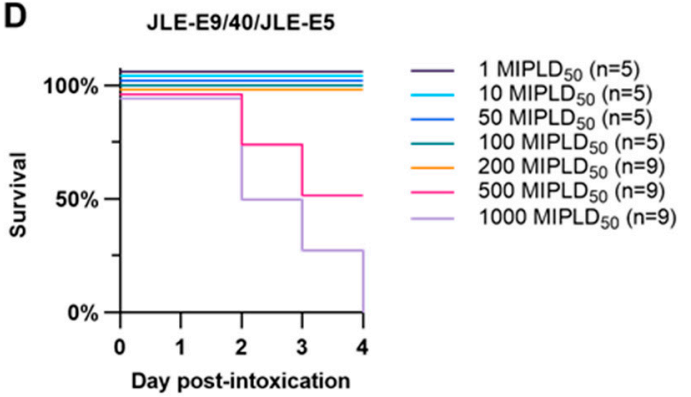

E

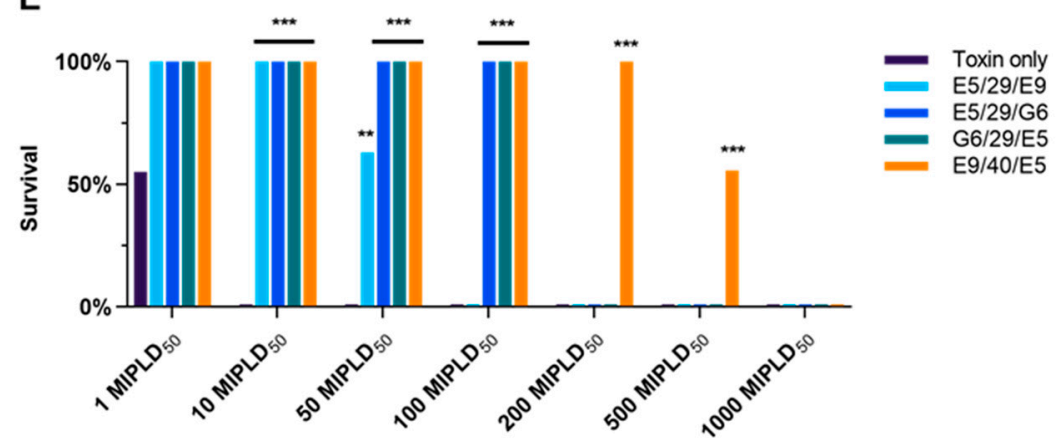

Figure 5. Heterodimer VNAs have radically improved protective efficacies in vivo. Heterodimeric VNAs were prepared containing four different combinations of the three BoNT/E-neutralizing VHHs identified in Tables 1 and 2. Mice were co-administered $2 \mu \mathrm{g}$ of the indicated VNA (40 pmol) and 1-1000 MIPLD ${ }_{50}$ BoNT/E by intravenous injection and survival was monitored over $4 \mathrm{~d}$. (A-D) Survival curves as a function of time post-exposure for JLE-E5/29/JLE-G6 (A), JLE-G6/29/JLE-E9 (B), JLE-E5/29/JLE-E9 (C) and JLE-E9/40/JLE-E5 (D). (E) Comparison of protective efficacies among VNAs at each BoNT/E challenge dose, with Bonferroni-adjusted significances shown against vehicle treatments at each dose. ${ }^{* * *} p<0.001, * * p<0.01$.

\section{Discussion}

In this paper, we report the discovery of 19 unique, unrelated VHHs recognizing a catalytically inactive form of BoNT/E called ciBoNTE (Tables 1 and 2). The ciBoNTE employed contains the complete sequence of BoNT/E holotoxin with only a few amino acids modified within the catalytic protease domain to render the toxin effectively inactive [29]. This and other similar catalytically inactive mutant holotoxins appear to retain most or all of the conformational form of the active holotoxins based on their excellent immunogenicity as antitoxins, the presence of a very low level of residual toxicity, and the demonstration that they possess similar receptor binding and crystal structure expected for the active toxin [33,34]. Indeed, we similarly employed catalytically inactivated mutants of BoNT/A and BoNT/B to obtain potent antitoxin VHHs to each serotype $[21,25]$. Of the 19 unique VHHs recognizing ciBoNTE that we identified, eight were demonstrated to possess significant BoNT/E neutralizing activity.

One major goal of the VHH discovery process targeting BoNT/E is to develop VHH-based antitoxin agents that lead to more effective BoNT antitoxin products. Because of their small size and stable structures, VHHs are highly amenable to multimerization which can dramatically improve the affinity and potency of the products and expand their specificities. This has been demonstrated for a variety of toxin targets including BoNT/A, BoNT/B, Shiga toxins, C. difficile toxins, anthrax and ricin $[11,13,16-18,21,25]$. The resulting heteromultimeric VHH-based neutralizing agents (VNAs) alone can be very effective in animal models of intoxication, but where necessary the potency can be further enhanced by co-administering the VNAs with an anti-tag effector antibody (efAb) which binds to two epitopic tags on each VNA to impart the antibody effector functions (e.g., promotion of serum clearance) resident in the Fc domains [16,21,35]. Another approach to enhancing the potency of VNAs 
is to employ structural information to facilitate the design of VNAs in which two VHH components are both sterically permitted to bind simultaneously to the target. This approach was recently validated as a tool to improve the antitoxin potency of VNAs targeting both BoNT/A and BoNT/B [25].

We report here the use of recent crystal structure and mechanistic data for two BoNT/E-neutralizing VHHs, JLE-E5 and JLE-E9 [28], and the use of these data to predict and then validate the mechanisms by which they neutralize intoxication of neurons. To test these VHHs as heterodimeric VNAs we prepared four different constructs, each containing two of the original three BoNT/E-neutralizing VHHs from Table 1 (JLE-E5, JLE-E9 and JLE-G6). The initial VNAs were designed before structural information became available and contained the three different possible pairs with the three VHHs. The fourth VNA exploited structural information showing that JLE-E5 and JLE-E9 bind nearby on BoNT/E and was designed with the VHH orientation and separating spacer length optimized to permit both $\mathrm{VHH}$ components to bind simultaneously on the toxin. As we expected based on our prior studies with other toxins, each of the heterodimers (dosed at 40 pmole/mouse) were capable of protecting mice from co-intoxication with lethal doses of BoNT/E, though having different upper limits on the toxin dose with which they were effective. The initial heterodimer consisting of the two VHHs, JLE-E5 and JLE-E9, which neutralize BoNT/E by the same mechanism (inhibiting $\mathrm{H}_{\mathrm{N}}$ membrane insertion, proved to be the least potent and protected mice only up to about $50 \mathrm{LD}_{50}$ BoNT/E. The two VNAs containing VHH pairs the neutralize BoNT/E by inhibiting both $\mathrm{H}_{\mathrm{N}}$ membrane insertion and receptor binding (JLE-G6) fully protected mice from $100 \mathrm{LD}_{50}$ BoNT/E. The fourth VNA in which the orientation and spacer length were optimized to freely permit simultaneous binding of JLE-E5 and JLE-E9 proved to be the most potent, protecting most mice to 500 LD $_{50}$ BoNT/E. Thus the 'designer VNA' was about $10 \times$ more potent than the other VNA with the same VHH components that lacked optimization for simultaneous binding. We now also report four new unique BoNT/E-neutralizing VHH monomers, and three of these appear to be more potent than the JLE panel VHHs (Tables 1 and 2) based on mouse studies with low dose toxin challenges. Once structural and mechanistic information is available with these VHHs from the JSI panel (Table 2), we anticipate the ability to design VNAs having substantially improved potencies.

The VHH phage display library from alpacas immunized with ciBoNTE or LC/E was initially panned by selection for phage binding to the two proteins coated onto standard Nunc Maxisorp plastic wells. This plastic offers both hydrophobic and hydrophilic binding sites to maximize adsorption of proteins. While this is an advantage for most proteins, coating to this surface can alter the conformation of some proteins [36]. We noted that all the numerous VHHs we obtained from panning on ciBoNT/E which showed recognition of LC/E fell into two homology groups which competed for the same epitope. A separate panning round on Maxisorp coated LC/E also yielded only similar VHHs in the same competition group. This group of 11 VHHs included 10 related VHHs best represented by JLG-G12, and all showed clear recognition of LC/E coated to protein-binding plastic but were virtually unable to bind to the soluble form of LC/E. Since VHH antibodies are known to be strongly dependent on target conformation for binding [37], we speculated that these $\mathrm{VHH}$ bound to a partially unfolded conformation of LC/E. We then re-panned the VHH-display phage library on soluble LC/E that had been captured to a surface with an antibody. The results were dramatically different as we identified a robust panel of 20 unique, unrelated $\mathrm{VHH}$ recognizing native LC/E, none of which were related to the JLG-G12 competition group.

These findings strongly suggested that the LC/E domain of ciBoNTE undergoes a major conformational change upon adsorption to a plastic surface. We do not believe that coating on plastic completely denatures LC/E because several members of the JLG-G12 family of VHHs were tested for recognition of LC/E on denaturing western blots and produced undetectable or very weak signals (not shown). In other studies, we found that ciBoNTE adsorbed to tissue culture plastic became much better recognized by JLG-G12 when the ciBoNTE was denatured by pretreatment with boiling phosphate-buffered saline (PBS) or $0.1 \mathrm{M} \mathrm{HCl}$ (Figure S9). Similar ciBoNTE treatments resulted, as expected, in near loss of binding by the JLE-E5 VHH which recognizes native ciBoNTE. The results 
seem more consistent with the hypothesis that LC/E is induced to become a stable, partially unfolded conformation recognized by the JLG-G12 family upon adsorption to plastic, more so on hydrophobic protein-binding plastic than tissue culture plastic. When tissue culture plastic-bound ciBoNTE is transiently denatured by heat or $\mathrm{pH}$, it refolds back into the partially unfolded state. It seems likely that this unusual lability of LC/E is a major reason for the notoriously poor expression and poor solubility of this protease [38]. We hypothesize that this extreme lability of shape upon plastic adsorption reflects an intrinsic rapid ability of LC/E to undergo the transition to a proposed 'molten globule' form during association with endosomal membrane while at lower $\mathrm{pH}$ undergoing neuronal transcytosis to the cytoplasm [39,40], and this unusual lability compared to other BoNT proteases [41] may be at least one reason why BoNT/E is such a fast-acting poison in animals. Future studies will seek to determine whether JLG-G12 recognizes a specific conformational epitope present in the molten globule state.

Because of the apparent lability of LC/E coated to plastic, we employed a LC/E-binding VHH, JSI-F7 (one of two such VHHs obtained by panning on captured ciBoNTE), as a LC/E capture agent to permit a new panning of our $\mathrm{VHH}$ display phage library on native protease. Using native LC/E target for panning, we discovered a robust panel of 20 new unique and unrelated VHHs (JVV and JVZ panels) that recognize epitopes on LC/E (Table 3). None of the VHHs identified in this panning were related to JLG-G12. Two of the new LC/E-binding VHHs, JVV-G3 and JVZ-E7, recognize captured ciBoNTE, both with sub-nM EC 50 . The remaining 18 VHHs in the JVV and JVZ panels must bind LC/E domain epitopes that are partially or completely hidden by the heavy chain within the holotoxin form. Of the 22 different unique LC/E binding VHHs in Table 3, 9 VHHs proved able to inhibit the SNAP-25 protease activity of LC/E. Intraneuronal delivery of LC/E protease inhibitor VHHs via biomolecular vehicles may be a viable approach to development of novel botulism antidotes capable of accelerating recovery from paralysis. Towards this goal, the cytosolic delivery of protein cargo to neurons has recently been demonstrated using heat-labile enterotoxin II [42] and atoxic mutants of BoNT [7,43].

\section{Conclusions}

In summary, we report the discovery and characterization of 19 unique VHHs capable of binding ciBoNTE holotoxin and 22 unique VHHs able to bind to soluble LC/E domain. Seven of the ciBoNTE-binding VHHs significantly inhibited BoNT/E intoxication of neurons. Heterodimers of two linked BoNT/E-neutralizing VHHs were highly protective of BoNT/E intoxication in mice, particularly a heterodimer that was optimized to permit simultaneous binding of both $\mathrm{VHH}$ components to the toxin. LC/E-binding VHHs were able to bind only to the protease when it was adsorbed to plastic or when it was immobilized suggesting the protease is highly labile and easily switches between a soluble form and a completely different conformation when associated with a hydrophobic surface. Nine VHHs recognizing soluble LC/E were capable of inhibiting its protease activity. These new VHHs may prove to be useful research reagents and valuable components of novel BoNT/E antitoxin and/or antidote therapeutics.

\section{Materials and Methods}

\subsection{Ethics Statement and Disclaimers}

Animal studies were conducted with the approval of Institutional Animal Care and Use Committees from the U.S. Army Medical Research Institute of Chemical Defense (USAMRICD) and Tufts Cummings School of Veterinary Medicine (TCSVM) conducted under Protocol G2016-74, 7/18/2016. All procedures were conducted in accordance with the principles stated in the Guide for the Care and Use of Laboratory Animals [44], and the Animal Welfare Act of 1966 (P.L. 89-544), as amended. Animal facilities were maintained in accordance with the Animal Welfare Act, United States Department of Agriculture Regulations (9 CFR, Parts 1, 2, and 3), and the Guide for the Care and Use of Laboratory Animals. USAMRICD and the Cummings School have Public Health Service-approved Animal Welfare Assurance Agreements (A4528-01 and A4059-01, respectively) on file with the NIH Office of Laboratory 
Animal Welfare. The views expressed in this manuscript are those of the authors and do not reflect the official policy of the Department of Army, Department of Defense, or the U.S. Government.

\subsection{Toxins and Reagents}

\subsubsection{BoNT/E Toxin and ciBoNTE Immunogen}

Purified single-chain botulinum neurotoxin serotype E (BoNT/E; Metabiologics, Inc.) was activated by a $60 \mathrm{~min}$ incubation at $37^{\circ} \mathrm{C}$ in $0.05 \mathrm{M}$ sodium phosphate buffer ( $\left.\mathrm{pH} 6.5\right), 0.3 \mathrm{mg} / \mathrm{mL}$ TPCK-treated trypsin (Sigma-Aldrich, St Louis, MO, USA) and 10\% glycerol [31]. Activated BoNT/E was diluted 1:4 with gelatin (Sigma-Aldrich; St. Louis, MO, USA) and stored at $-80{ }^{\circ} \mathrm{C}$ until use. The mouse intraperitoneal median lethal dose (MIPLD ${ }_{50}$ ) of each lot of activated BoNT/E was determined by simple logistical regression using the mouse lethal assay [45]. Prior to injection, BoNT/A was diluted to various working concentrations in PBS with $0.2 \%$ gelatin (ThermoFisher, Waltham, MA, USA). Sheep anti-BoNT/E antiserum was produced, and its potency determined, as previously described [21]. The ciBoNTE [33] was kindly provided by Dr. Robert Webb, USAMRIID. Antibodies used were mouse anti-SNAP25 antibody (SMI-81; Sigma); goat anti-rabbit HRP antiserum (Sigma); HRP anti-E-tag mAb (Bethyl).

\subsubsection{LC/E Protein}

The expression construct for the light chain of BoNT/E1, called LC/E, was designed and synthesized for optimized expression in E. coli with tandem affinity tags-8His residues on the $\mathrm{N}$-terminus and 3 streptag II repeats on the C-terminus. Affinity tags were separated from the sequence of the LC/E1 (aa 2-403) by the sequence recognized and cleaved by Tobacco Etch Virus (TEV) protease. The synthetic gene with affinity tags was subcloned into pET28a $\mathrm{Kan}^{+}$expression vector and transformed into BL21(DE3) E. coli expression host. Protein expression was performed in auto-induction medium [46]. Briefly, a single colony of E. coli was grown overnight in $50 \mathrm{~mL}$ of ZYM5052 medium (Studier) supplemented with $100 \mu \mathrm{g} / \mathrm{mL}$ kanamycin at $37^{\circ} \mathrm{C}, 250 \mathrm{rpm}$, in $125 \mathrm{~mL}$ baffled flask (final $\mathrm{OD}_{600} \sim 7-12$ ). In total, $500 \mathrm{~mL}$ of freshly prepared ZYM5052 medium in $2 \mathrm{~L}$ baffled flask supplemented with $100 \mu \mathrm{g} / \mathrm{mL}$ kanamycin was inoculated with $1.5 \mathrm{~mL}$ of the overnight culture and grown at $37^{\circ} \mathrm{C}, 300 \mathrm{rpm}$, until $\mathrm{OD}_{600}$ reached $\sim 0.5$. Once $\mathrm{OD}_{600} \sim 0.5$ was reached, growing continued for $16 \mathrm{~h}$ at $18^{\circ} \mathrm{C}, 275 \mathrm{rpm}$. At $16 \mathrm{~h}$ cells were harvested by centrifugation $\left(5000 \mathrm{~g}, 4^{\circ} \mathrm{C}, 0.5 \mathrm{~h}\right)$ and resuspended in ice-cold Buffer A ( $500 \mathrm{mM} \mathrm{NaCl}, 25 \mathrm{mM}$ sodium phosphate, $\mathrm{pH}$ 8.0, 1 g cell paste / $10 \mathrm{~mL}$ buffer), supplemented with protease inhibitors (Thermo Fisher Scientific, Cat A32965, 1 tablet for every $50 \mathrm{~mL}$ of suspension). The cell suspension was lysed by three passes using Avesin EmulsiFlex C-3 homogenizer (PRC). Triton X-100 was added to the lysate to a final concentration $0.1 \%$ and the mixture was kept on a stirring plate for $0.5 \mathrm{~h}$ at $4{ }^{\circ} \mathrm{C}$. Subsequently the lysate was cleared by centrifugation (Ti- 45 rotor, $\sim 40000 \mathrm{rpm}, 0.5 \mathrm{~h}, 4{ }^{\circ} \mathrm{C}$ ) and the supernatant was collected. Supernatant was loaded on the $\mathrm{Ni}^{2+}-\mathrm{NTA}$ resin (Qiagen, $\sim 20 \mathrm{~mL}$ bed volume), pre-equilibrated with Buffer A supplemented with $0.1 \%$ Triton $\mathrm{X}-100$. After loading, the column was washed with 5 volumes of Buffer A supplemented with $0.1 \%$ Triton X-100, and subsequently with 5 volumes of Buffer A supplemented with $10 \mathrm{mM}$ and $30 \mathrm{mM}$ imidazole. The fraction containing the enriched LC/E was eluted with 5 volumes of Buffer A $(\sim 100 \mathrm{~mL})$ supplemented with $300 \mathrm{mM}$ imidazole, final $\mathrm{pH}$ 8.0. Protease inhibitors (1 tablet for $50 \mathrm{~mL}$ ) and EDTA (to final concentration $5 \mathrm{mM}$ ) were added to the $\mathrm{Ni}^{2+}$-NTA eluate and the mixture was loaded on the Streptactin high capacity resin (IBA Gmbh, bed volume $\sim 20 \mathrm{~mL}$ ), pre-equilibrated with Buffer A, supplemented with $300 \mathrm{mM}$ imidazole, $5 \mathrm{mM}$ EDTA. After loading, the column was subsequently washed with 10 volumes of Buffer $\mathrm{B}(1 \mathrm{M} \mathrm{NaCl}, 50 \mathrm{mM}$ sodium phosphate, $5 \mathrm{mM}$ EDTA, final $\mathrm{pH}$ 8.0), 10 volumes of Buffer $\mathrm{C}(100 \mathrm{mM} \mathrm{NaCl}, 25 \mathrm{mM}$ sodium phosphate, $10 \%$ glycerol, $5 \mathrm{mM}$ EDTA, final $\mathrm{pH}$ 8.0) and protein was eluted in 10 volumes $(\sim 200 \mathrm{~mL})$ of Buffer C supplemented with $10 \mathrm{mM}$ D-desthiobiotin. The eluate was concentrated $\sim 50$ fold using spin concentrators $10 \mathrm{~K}$ MWCO at $\sim 3000 \mathrm{~g}$. The LC/E was further by size exclusion chromatography on a HiLoad 26/600 Superdex 200 pg column 
(GE) equilibrated with buffer C. Fractions containing LC/E were consolidated and, concentrated using spin concentrators $10 \mathrm{~K}$ MWCO at $\sim 3000 \mathrm{~g}$, then diluted 1:1 v/v with Buffer C, 80\% glycerol. The protein concentration was determined with Pierce BCA Protein Assay kit (Thermo Fisher Scientific). Protein was aliquoted and stored at $-20^{\circ} \mathrm{C}$.

\subsection{Alpaca Immunization, VHH Discovery and Purification of Recombinant Proteins}

Four alpacas were immunized at different times with various antigens representing BoNT/E. Two alpacas were immunized with glutathione-S-transferase fusion proteins to LC/E (kindly provided by Dr. Randall Kincaid). Two alpacas were immunized with a pool of purified recombinant catalytically inactive BoNT/E holotoxin, subtype 1 (ciBoNTE) and recombinant LC/E. All alpacas were immunized by five multi-site subcutaneous (SC) injections at approximate 3-week intervals essentially as previously described [17]. Between 3 to 5 days following the fifth immunization, blood was obtained for lymphocyte preparation. RNA was prepared from lymphocytes using the QIAshredder homogenizer and RNeasy Plus Mini kit (Qiagen, Valencia, CA, USA) as recommended by the manufacturer. Two VHH-display phage libraries were prepared, each from the lymphocyte RNA from pools of two alpacas, essentially as described previously [11]. Two different VHH-display phage libraries were prepared, each having a complexity of $>10^{7}$ independent clones with $>95 \%$ containing $\mathrm{VHH}$ inserts.

The VHH-display phage libraries were panned to enrich and then identify VHHs binding to ciBoNTE or to LC/E using methods essentially as previously described [11,21]. Briefly, following two rounds of panning to a protein, clones expressing $\mathrm{VHH}$ that recognize the protein were identified by ELISA and compared by DNA fingerprinting [16]. VHH coding DNA was obtained for clones with distinct fingerprints and aligned. One $\mathrm{VHH}$ representing each unique, clonally related family (i.e., containing clear CDR homology) was selected for soluble expression and purification (see below). Early VHHs were obtained by panning on $1 \mu \mathrm{g} / \mathrm{mL}$ ciBoNTE (JLE, JLF, JLG series) or $1 \mu \mathrm{g} / \mathrm{mL}$ LC/E that had been immobilized on protein-binding plastic. To select for VHHs binding to more conformationally native ciBoNTE, later panning was performed on $1 \mu \mathrm{g} / \mathrm{mL}$ ciBoNTE that had been captured onto Nunc Immuno Tubes previously coated with $5 \mu \mathrm{g} / \mathrm{mL}$ of purified JLE-E5 VHH expressed with a myc tag (JSI series). Similarly, VHHs recognizing native LC/E were selected on $1 \mu \mathrm{g} / \mathrm{mL} \mathrm{LC/E} \mathrm{that} \mathrm{was}$ captured onto plastic previously coated with $5 \mu \mathrm{g} / \mathrm{mL}$ of JSI-F7 expressed with a myc tag (JVV and JVZ series). VHHs that displayed good binding properties for ciBoNTE as purified proteins are shown in Tables 1 and 2. Unique VHHs showing good binding properties to LC/E are shown in Table 3. The VHH coding DNAs were expressed and purified from E. coli as thioredoxin (Trx) fusion proteins with a carboxy-terminal E-tag, or as VHHs lacking Trx with myc tags, as previously described [21]. VHH heterodimers were encoded as synthetic DNA and similarly expressed and purified as Trx fusion proteins. The VHHs in the heterodimers were initially separated by 29 amino acids containing the VHH hinge region and a 15 amino acid spacer (GGGGS) 3 . The optimized heterodimer, JLE-E9/40/JLE-E5, lacked the hinge region and contained a (GGGGS) ${ }_{8}$ spacer.

\subsection{Dilution ELISAs}

ELISAs were performed employing either protein-binding or tissue culture 96-well plates. For capture ELISAs, the capturing agent was typically $5 \mu \mathrm{g} / \mathrm{mL}$ of a VHH expressed with an amino terminal $6 \mathrm{His}$ tag and a carboxyl terminal myc tag. Where indicated, $5 \mu \mathrm{g} / \mathrm{mL}$ of streptavidin was coated to capture LC/E that was expressed with a carboxyl terminal strep-tag. For VHH capture ELISAs, we employed VHHs expressed with a myc tag and coated at $5 \mathrm{ug} / \mathrm{mL}$. BoNT/E protein targets were typically coated at $1 \mathrm{ug} / \mathrm{mL}$ overnight at $4{ }^{\circ} \mathrm{C}$ in PBS. All coated proteins were blocked for at least an hour at $37^{\circ} \mathrm{C}$ with $4 \%$ milk in PBS, $0.1 \%$ Tween. For streptavidin or VHH capture ELISAs, the target (ciBoNTE or LC/E) was incubated at $1 \mu \mathrm{g} / \mathrm{mL}$ for one hour at $37^{\circ} \mathrm{C}$ with $4 \%$ milk in PBS, $0.1 \%$ Tween. After washing, dilution ELISAs were then initiated by diluting the test VHHs (expressed in pET-32 with an amino terminal thioredoxin and a carboxyl terminal E-tag) to $125 \mathrm{nM}$ and performing serial dilutions of $1: 5$. After incubation for one hour at $37^{\circ} \mathrm{C}$, plates were washed and then incubated 
with 1:10,000 goat HRP/anti-E-tag (Bethyl) for one hour, washed, developed with TMB (Sigma) as recommended by manufacturer and read at A450.

\subsection{Competition Assays}

Competition assays were performed essentially as previously described [21]. In some cases, in place of phage, we employed soluble, purified VHHs expressed with myc tags, as competitors in ELISA assays detecting target binding by purified VHHs expressed with E-tags.

\subsection{Cell-Based BoNT/E Neutralization Assays}

Prescreening assays to assess the BoNT/E neutralizing activity of the first set of VHHs were performed using methods very similar to those reported previously [47] for BoNT/A except that $2.5 \mathrm{nM}$ BoNT/E was used in the overnight incubations. Cell-based assays for VHH neutralization of BoNT/E were conducted using fresh E18 rat hippocampal, cortical and ventricular zone tissues obtained from BrainBits (Springfield, IL, USA), dissociated according to the manufacturer's instructions, and plated at a density of 175,000 cells $/ \mathrm{cm}^{2}$ in 12-well plates coated with polyethylenimine and laminin (Sigma-Aldrich) as previously described [31,48]. Neuronal cultures were maintained at $5 \% \mathrm{CO}_{2}, 37^{\circ} \mathrm{C}$, and $95 \%$ humidity in NbActiv4 medium (BrainBits). Experiments were performed 17 to 21 days after plating. For neuronal intoxication, $167 \mathrm{pM}$ BoNT/E was pre-mixed with $2 \mathrm{uM}$ of each VHH or VNA in conditioned medium supplemented with $0.2 \%$ gelatin (Sigma) for $15 \mathrm{~min}$ at $37^{\circ} \mathrm{C}$ and added 1:10 to neurons to a final concentration of $16.7 \mathrm{pM} \mathrm{BoNT/E} \mathrm{(20} \mathrm{MIPLD50/mL)} \mathrm{and} 200 \mathrm{nM}$ each VHH or VNA. Controls included naïve neurons, sheep anti-BoNT/E antiserum and vehicle treatments. Neurons were lysed after $24 \mathrm{~h}$ and protein from neuronal cultures was harvested, quantified by BCA (Pierce), separated by SDS-PAGE and transferred to PVDF. Blots were stained using primary antibodies against SNAP-25 (SMI-81; Covance, Princeton, NJ, USA) and STX1 (110011; Synaptic Systems, Gottingen, Germany) and visualized using goat anti-mouse secondaries conjugated to Alexa Fluor 488 (Invitrogen, Carlsbad, CA, USA) for detection of STX1 (33 kDa) and intact or cleaved SNAP-25 (18 or $25 \mathrm{kDa}$, respectively). The percentage of cleaved SNAP- 25 was determined by densitometry, normalized to toxin-only controls within each experimental and averaged among experiments. Studies were averaged among 2-4 assays for treatments that showed efficacy.

\subsection{LC/E Protease Inhibition Assay}

Initial assays to screen $\mathrm{VHHs}$ for their ability to inhibit LC/E protease were performed using the Repcon 5 substrate provided by the Ichtchenko lab. This protein consists of rat SNAP-25 aa 128-206 flanked by 12 histidines and mWasabi on the amino side and rat VAMP aa 2-96, 3 copies of streptag and avitag on the carboxyl side. This $56 \mathrm{kDa}$ protein is cleaved into a $36 \mathrm{kDa}$ and $20 \mathrm{kDa}$ product upon cleavage by LC/E. Incubations were at $37^{\circ} \mathrm{C}$ performed in $20 \mathrm{mM}$ HEPES $\mathrm{pH}$ 8.0, $20 \mu \mathrm{M}$ zinc acetate and $0.1 \%$ Tween-20. Unless otherwise indicated, reactions were $40 \mu \mathrm{l}$ containing $40 \mathrm{ng}$ of LC/E, $400 \mathrm{ng}$ of purified recombinant VHH protein and $4 \mu \mathrm{g}$ of Repcon5. After $90 \mathrm{~min}$, a $20 \mu \mathrm{L}$ aliquot of the reaction were added to $20 \mu \mathrm{L}$ of $2 \times \mathrm{SDS}$ sample buffer and placed in a $10{ }^{\circ} \mathrm{C}$ heat block for $5 \mathrm{~min}$. SDS PAGE was performed on $10 \mu \mathrm{l}$ aliquots of the samples. Substrate cleavage was detected by Western blotting with HRP/anti-hexahistidine (Santa Cruz). Assays were repeated on all VHHs at least three times. BoTest ${ }^{\circledR}$ assays were performed basically as recommended by the manufacturer (BioSentinel). For these assays, we employed $25 \mathrm{ng} / \mathrm{mL}$ of LC/E and variable amounts of VHHs.

\subsection{Standard Mouse Toxin Lethality Assay}

BoNT/E protection studies were conducted in male CD-1 mice (10-14 weeks of age; Charles River Laboratories, Wilmington, MA (female mice used only in Figure S8)). Mice were group-housed, maintained on a $12 \mathrm{~h}$ diurnal cycle and provided a standard diet with regular enrichment and water ad libitum. Mice weighing 24-28 g were randomly assigned to groups for all experiments. Intoxication was performed by diluting 1-1000 MIPLD 50 BoNT/E in a total volume of $200 \mathrm{uL}$ PBS supplemented 
with $0.2 \%$ gelatin (Sigma) and $2 \mu \mathrm{g}(40 \mathrm{pmol})$ of each VHH or VNA. The mixture was incubated at $37^{\circ} \mathrm{C}$ for 15-30 min and administered to mice by tail vein injection. Survival was monitored at $24 \mathrm{~h}$ intervals over 4 to 7 days. To minimize animal distress, mice were euthanized if they presented with terminal signs of botulism such as severe agonal breathing and total paralysis, as previously described [49]. Typical study sizes were 3-5 mice per group, repeated 2-3 times. Survival outcomes among 3 or more groups were initially compared using the Chi-square test. If significant differences existed within the experimental group $(p<0.05)$, Fisher's exact test was used to make pairwise comparisons against vehicle controls. To compensate for multiple hypothesis testing, the Bonferroni-adjusted significance threshold was determined by dividing 0.05 by the total number of pairwise comparisons.

\subsection{Gel Filtration Analysis}

$\mathrm{LCH}_{\mathrm{N}} / \mathrm{E}(\mathrm{M} 1-\mathrm{K} 845)$ was purified as described [28]. In total, $0.8 \mu \mathrm{M}$ of $\mathrm{LCH}_{\mathrm{N}} / \mathrm{E}$ was incubated with JLE-E5/29/JLE-E9 or JLE-E9/40/JLE-E5 at a $\mathrm{LCH}_{\mathrm{N}} / \mathrm{E}: \mathrm{VNA}=2: 1$ molar ratio in PBS at $4{ }^{\circ} \mathrm{C}$ for $1 \mathrm{~h}$. The protein mixtures, the individual VNA, or the $\mathrm{LCH}_{\mathrm{N}} / \mathrm{E}$ was then separated by Superdex-200 size-exclusion chromatography in PBS. The experiment was performed in duplicate.

Supplementary Materials: The following are available online at http://www.mdpi.com/2072-6651/12/10/611/s1, Figure S1: Dilution ELISAs of all ciBoNTE-binding VHHs tested on plastic coated ciBoNTE and LC/E, Figure S2: Dilution ELISAs of all JSI-series VHHs for captured ciBoNTE or LC/E, Figure S3: Dilution ELISAs of LC/E-binding VHHs on plastic coated or antibody-captured LC/E. Figure S4: Screening of LC/E-binding VHHs for protease inhibition activity, Figure S5: A subset of VHHs and VNAs have neutralizing properties in rat primary neuron cultures, Figure S6: Summary of cell-based SNAP-25 cleavage assays for non-neutralizing VHHs, Figure S7: Select VHH monomers are able to protect mice from co-intoxication with 3 MIPLD50 BoNT/E, Figure S8: Second site study testing the BoNT/E antitoxin potency of three VHH heterodimers in mice, Figure S9: The JLG-G12 VHH family recognizes a stable, partially unfolded ciBoNTE conformation.

Author Contributions: Conceptualization, C.B.S., methodology, J.M.T., E.V.-C., K.-H.L., J.M., D.B., C.A.O., M.T.C., S.M.L.B., B.M.W., R.P.W., K.I., R.J., P.M.M., C.B.S., formal analysis, J.M., P.M.M., C.B.S., investigation, J.M.T., E.V.-C., K.-H.L., J.M., C.A.O., M.T.C., S.M.L.B., B.M.W., data curation, J.M., P.M.M., C.B.S., resources, R.P.W., supervision, J.M., K.I., R.J., P.M.M., C.B.S., writing, J.M., K.I., R.J., K.-H.L., P.M.M., C.B.S., funding acquisition, R.J., K.I., C.B.S. All authors have read and agreed to the published version of the manuscript.

Funding: This work was supported in part by grants U54-AI057159, R01AI125704 and R01AI093467 (CBS), R01 AI125704 (RJ, CBS), and RAI093504 (KI) from NIH NIAID. The content is solely the responsibility of the authors and does not necessarily represent the official views of the National Institute of Allergy and Infectious Diseases, the National Institutes of Health or the Department of Defense.

Acknowledgments: We gratefully acknowledge the excellent assistance of Karen Baldwin, Kwasi Ofori and Zachary Forbes for expert handling of alpacas, isolation of PBLs, performance of mouse assays and preparation and quantitation of activated BoNT/E. Authors also acknowledge the excellent help of Michelle Debatis and Sue Chapman in performing the toxin neutralization and protease inhibition pre-screening assays, and Jaclyn Cika and Cesar Benjumea (NYU SoM) for protein purification.

Conflicts of Interest: The authors declare no conflict of interest. The funders had no role in the design of the study; in the collection, analyses, or interpretation of data; in the writing of the manuscript, or in the decision to publish the results.

\section{References}

1. Dong, M.; Masuyer, G.; Stenmark, P. Botulinum and Tetanus Neurotoxins. Annu. Rev. Biochem. 2019, 88, 811-837. [CrossRef] [PubMed]

2. Arnon, S.S. Creation and development of the public service orphan drug Human Botulism Immune Globulin. Pediatrics 2007, 119, 785-789. [CrossRef]

3. Centers for Disease Control and Prevention. Investigational heptavalent botulinum antitoxin (HBAT) to replace licensed botulinum antitoxin $\mathrm{AB}$ and investigational botulinum antitoxin E. Morb. Mortal. Wkly. Rep. 2010, 59, 299.

4. Nayak, S.U.; Griffiss, J.M.; McKenzie, R.; Fuchs, E.J.; Jurao, R.A.; An, A.T. Safety and pharmacokinetics of XOMA $3 \mathrm{AB}$, a novel mixture of three monoclonal antibodies against botulinum toxin A. Antimicrob. Agents Chemother. 2014, 58, 5047-5053. [CrossRef] 
5. Snow, D.M.; Riling, K.; Kimbler, A.; Espinoza, Y.; Wong, D.; Pham, K. Safety and Pharmacokinetics of a Four Monoclonal Antibody Combination Against Botulinum C and D Neurotoxins. Antimicrob. Agents Chemother. 2019, 63. [CrossRef] [PubMed]

6. Dock, M.; Ben Ali, A.; Karras, A.; Misset, B.; Garrouste-Orgeas, M.; Deletie, E. [Treatment of severe botulism with 3,4-diaminopyridine]. La Presse Med. 2002, 31, 601-602.

7. Vazquez-Cintron, E.J.; Beske, P.H.; Tenezaca, L.; Tran, B.Q.; Oyler, J.M.; Glotfelty, E.J. Engineering Botulinum Neurotoxin C1 as a Molecular Vehicle for Intra-Neuronal Drug Delivery. Sci. Rep. 2017, 7, 42923. [CrossRef]

8. Thanongsaksrikul, J.; Chaicumpa, W. Botulinum neurotoxins and botulism: A novel therapeutic approach. Toxins 2011, 3, 469-488. [CrossRef]

9. Alirahimi, E.; Kazemi-Lomedasht, F.; Shahbazzadeh, D.; Habibi-Anbouhi, M.; Hosseininejad, C.M.; Sotoudeh, N. Nanobodies as novel therapeutic agents in envenomation. Biochim. Biophys. Acta Gen. Subj. 2018, 1862, 2955-2965. [CrossRef]

10. Muyldermans, S. Nanobodies: Natural single-domain antibodies. Annu. Rev. Biochem. 2013, 82, $775-797$. [CrossRef]

11. Moayeri, M.; Leysath, C.E.; Tremblay, J.M.; Vrentas, C.; Crown, D.; Leppla, S.H. A Heterodimer of a VHH Antibody that Inhibits Anthrax Toxin Cell Binding Linked to a VHH that Blocks Oligomer Formation is Highly Protective in an Anthrax Spore Challenge Model. J. Biol. Chem. 2015. [CrossRef]

12. Mukherjee, J.; Dmitriev, I.; Debatis, M.; Tremblay, J.M.; Beamer, G.; Kashentseva, E.A. Prolonged prophylactic protection from botulism with a single adenovirus treatment promoting serum expression of a VHH-based antitoxin protein. PLoS ONE 2014, 9, e106422. [CrossRef]

13. Vance, D.J.; Tremblay, J.M.; Mantis, N.J.; Shoemaker, C.B. Stepwise engineering of heterodimeric single domain camelid $\mathrm{VHH}$ antibodies that passively protect mice from ricin toxin. J. Biol. Chem. 2013, 288, 36538-36547. [CrossRef] [PubMed]

14. Schmidt, D.J.; Beamer, G.; Tremblay, J.M.; Steele, J.A.; Kim, H.B.; Wang, Y. A Tetraspecific VHH-based Neutralizing Antibody Modifies Disease Outcome in Three Animal Models of Clostridium difficile Infection. Clin. Vaccine Immunol. 2016, 23, 774-784. [CrossRef] [PubMed]

15. Sheoran, A.S.; Dmitriev, I.P.; Kashentseva, E.A.; Cohen, O.; Mukherjee, J.; Debatis, M. Adenovirus vector expressing Stx1/Stx2-neutralizing agent protects piglets infected with Escherichia coli O157:H7 against fatal systemic intoxication. Infect. Immun. 2015, 83, 286-291. [CrossRef]

16. Tremblay, J.M.; Mukherjee, J.; Leysath, C.E.; Debatis, M.; Ofori, K.; Baldwin, K. A single VHH-based toxin-neutralizing agent and an effector antibody protect mice against challenge with Shiga toxins 1 and 2. Infect. Immun. 2013, 81, 4592-4603. [CrossRef] [PubMed]

17. Vrentas, C.E.; Moayeri, M.; Keefer, A.B.; Greaney, A.J.; Tremblay, J.; O’Mard, D. A diverse set of single-domain antibodies (VHHs) against the anthrax toxin lethal and edema factors provides a basis for construction of a bispecific agent that protects against anthrax infection. J. Biol. Chem. 2016, 291, 21596-21606. [CrossRef] [PubMed]

18. Yang, Z.; Schmidt, D.; Liu, W.; Li, S.; Shi, L.; Sheng, J. A novel multivalent, single-domain antibody targeting TcdA and TcdB prevents fulminant Clostridium difficile infection in mice. J. Infect. Dis. 2014, 210, 964-972. [CrossRef]

19. Sepulveda, J.; Mukherjee, J.; Tzipori, S.; Simpson, L.L.; Shoemaker, C.B. Efficient serum clearance of botulinum neurotoxin achieved using a pool of small antitoxin binding agents. Infect. Immun. 2010, 78, 756-763. [CrossRef]

20. Thran, M.; Mukherjee, J.; Ponisch, M.; Fiedler, K.; Thess, A.; Mui, B.L. mRNA mediates passive vaccination against infectious agents, toxins, and tumors. EMBO Mol. Med. 2017, 9, 1434-1447. [CrossRef]

21. Mukherjee, J.; Tremblay, J.M.; Leysath, C.E.; Ofori, K.; Baldwin, K.; Feng, X. A novel strategy for development of recombinant antitoxin therapeutics tested in a mouse botulism model. PLoS ONE 2012, 7, e29941. [CrossRef]

22. Tremblay, J.M.; Kuo, C.L.; Abeijon, C.; Sepulveda, J.; Oyler, G.; Hu, X. Camelid single domain antibodies (VHHs) as neuronal cell intrabody binding agents and inhibitors of Clostridium botulinum neurotoxin (BoNT) proteases. Toxicon 2010, 56, 990-998. [CrossRef] [PubMed]

23. Godakova, S.A.; Noskov, A.N.; Vinogradova, I.D.; Ugriumova, G.A.; Solovyev, A.I.; Esmagambetov, I.B. Camelid VHHs Fused to Human Fc Fragments Provide Long Term Protection Against Botulinum Neurotoxin A in Mice. Toxins 2019, 11, 464. [CrossRef] [PubMed] 
24. Dong, J.; Thompson, A.A.; Fan, Y.; Lou, J.; Conrad, F.; Ho, M. A single-domain llama antibody potently inhibits the enzymatic activity of botulinum neurotoxin by binding to the non-catalytic alpha-exosite binding region. J. Mol. Biol. 2010, 397, 1106-1118. [CrossRef]

25. Lam, K.H.; Tremblay, J.M.; Vazquez-Cintron, E.; Perry, K.; Ondeck, C.; Webb, R.P. Structural Insights into Rational Design of Single-Domain Antibody-Based Antitoxins against Botulinum Neurotoxins. Cell Rep. 2020, 30, 2526-2539.e6. [CrossRef]

26. Bakherad, H.; Gargari, S.L.M.; Rasooli, I.; Rajabibazl, M.; Mohammadi, M.; Ebrahimizadeh, W. In vivo neutralization of botulinum neurotoxins serotype E with heavy-chain camelid antibodies (VHH). Mol. Biotechnol. 2013, 55, 159-167. [CrossRef] [PubMed]

27. Huang, N.J.; Pishesha, N.; Mukherjee, J.; Zhang, S.; Deshycka, R.; Sudaryo, V. Genetically engineered red cells expressing single domain camelid antibodies confer long-term protection against botulinum neurotoxin. Nat. Commun. 2017, 8, 423. [CrossRef]

28. Lam, K.H.; Perry, K.; Shoemaker, C.B.; Jin, R. Two VHH antibodies neutralize botulinum neurotoxin E1 by blocking its membrane translocation in host cells. Toxins 2020, in press.

29. Webb, R.P.; Smith, T.J.; Smith, L.A.; Wright, P.M.; Guernieri, R.L.; Brown, J.L. Recombinant Botulinum Neurotoxin Hc Subunit (BoNT Hc) and Catalytically Inactive Clostridium botulinum Holoproteins (ciBoNT HPs) as Vaccine Candidates for the Prevention of Botulism. Toxins 2017, 9, 269. [CrossRef]

30. Lerman, M.J.; Lembong, J.; Muramoto, S.; Gillen, G.; Fisher, J.P. The Evolution of Polystyrene as a Cell Culture Material. Tissue Eng. Part B Rev. 2018, 24, 359-372. [CrossRef]

31. Beske, P.H.; Bradford, A.B.; Grynovicki, J.O.; Glotfelty, E.J.; Hoffman, K.M.; Hubbard, K.S. Botulinum and Tetanus Neurotoxin-Induced Blockade of Synaptic Transmission in Networked Cultures of Human and Rodent Neurons. Toxicol. Sci. 2016, 149, 503-515. [CrossRef] [PubMed]

32. Zhou, H.X. Quantitative account of the enhanced affinity of two linked scFvs specific for different epitopes on the same antigen. J. Mol. Biol. 2003, 329, 1-8. [CrossRef]

33. Webb, R.P.; Smith, T.J.; Wright, P.; Brown, J.; Smith, L.A. Production of catalytically inactive BoNT/A1 holoprotein and comparison with BoNT/A1 subunit vaccines against toxin subtypes A1, A2, and A3. Vaccine 2009, 27, 4490-4497. [CrossRef] [PubMed]

34. Webb, R.; Wright, P.M.; Brown, J.L.; Skerry, J.C.; Guernieri, R.L.; Smith, T.J. Potency and stability of a trivalent, catalytically inactive vaccine against botulinum neurotoxin serotypes $\mathrm{C}$, E and F (triCEF). Toxicon 2020, 176, 67-76. [CrossRef]

35. Vance, D.J.; Tremblay, J.M.; Rong, Y.; Angalakurthi, S.K.; Volkin, D.B.; Middaugh, C.R. High-Resolution Epitope Positioning of a Large Collection of Neutralizing and Nonneutralizing Single-Domain Antibodies on the Enzymatic and Binding Subunits of Ricin Toxin. Clin. Vaccine Immunol. 2017, 24. [CrossRef]

36. Nizak, C.; Moutel, S.; Goud, B.; Perez, F. Selection and application of recombinant antibodies as sensors of rab protein conformation. Methods Enzymol. 2005, 403, 135-153. [CrossRef]

37. Pardon, E.; Laeremans, T.; Triest, S.; Rasmussen, S.G.; Wohlkonig, A.; Ruf, A. A general protocol for the generation of Nanobodies for structural biology. Nat. Protoc. 2014, 9, 674-693. [CrossRef]

38. Chen, S.; Barbieri, J.T. Solubility of the catalytic domains of Botulinum neurotoxin serotype E subtypes. Protein Expr. Purif. 2016, 118, 18-24. [CrossRef]

39. Puhar, A.; Johnson, E.A.; Rossetto, O.; Montecucco, C. Comparison of the $\mathrm{pH}$-induced conformational change of different clostridial neurotoxins. Biochem. Biophys. Res. Commun. 2004, 319, 66-71. [CrossRef]

40. Cai, S.; Kukreja, R.; Shoesmith, S.; Chang, T.W.; Singh, B.R. Botulinum neurotoxin light chain refolds at endosomal $\mathrm{pH}$ for its translocation. Protein J. 2006, 25, 455-462. [CrossRef]

41. Kumar, R.; Kukreja, R.V.; Cai, S.; Singh, B.R. Differential role of molten globule and protein folding in distinguishing unique features of botulinum neurotoxin. Biochim. Biophys. Acta 2014, 1844, 1145-1152. [CrossRef]

42. Chen, C.; Przedpelski, A.; Tepp, W.H.; Pellett, S.; Johnson, E.A.; Barbieri, J.T. Heat-Labile Enterotoxin IIa, a Platform To Deliver Heterologous Proteins into Neurons. mBio 2015, 6, e00734. [CrossRef]

43. Bade, S.; Rummel, A.; Reisinger, C.; Karnath, T.; Ahnert-Hilger, G.; Bigalke, H. Botulinum neurotoxin type D enables cytosolic delivery of enzymatically active cargo proteins to neurones via unfolded translocation intermediates. J. Neurochem. 2004, 91, 1461-1472. [CrossRef]

44. Council, N.R. Guide for the Care and Use of Laboratory Animals, 8th ed.; The National Academies Press: Washington, DC, USA, 2011; 246p. 
45. Pearce, L.B.; Borodic, G.E.; First, E.R.; MacCallum, R.D. Measurement of botulinum toxin activity: Evaluation of the lethality assay. Toxicol. Appl. Pharmacol. 1994, 128, 69-77. [CrossRef]

46. Studier, F.W. Protein production by auto-induction in high density shaking cultures. Protein Expr. Purif. 2005, 41, 207-234. [CrossRef]

47. Eubanks, L.M.; Silhar, P.; Salzameda, N.T.; Zakhari, J.S.; Xiaochuan, F.; Barbieri, J.T. Identification of a Natural Product Antagonist against the Botulinum Neurotoxin Light Chain Protease. ACS Med. Chem. Lett. 2010, 1, 268-272. [CrossRef]

48. Gut, I.M.; Beske, P.H.; Hubbard, K.S.; Lyman, M.E.; Hamilton, T.A.; McNutt, P.M. Novel application of stem cell-derived neurons to evaluate the time- and dose-dependent progression of excitotoxic injury. PLoS ONE 2013, 8, e64423. [CrossRef]

49. Vazquez-Cintron, E.; Machamer, J.; Ondeck, C.; Pagarigan, K.; Winner, B.; Bodner, P. Symptomatic treatment of botulism with a clinically approved small molecule. JCI Insight 2020, 5. [CrossRef] [PubMed]

(C) 2020 by the authors. Licensee MDPI, Basel, Switzerland. This article is an open access article distributed under the terms and conditions of the Creative Commons Attribution (CC BY) license (http://creativecommons.org/licenses/by/4.0/). 